\section{Perceived vs retinal relationships in the Ponzo illusion}

\author{
ROBERT T. HENNESSY and HERSCHEL W. LEIBOWITZ \\ The Pennsylvania State University, University Park, Pa. 16802
}

In order to evaluate the relative contribution of perceived and retinal image relationships as determiners of the Ponzo perspective illusion, the comparison lines were located physically either in the same plane as the background converging lines or in a separate plane nearer to the $O$. Data from 24 Ss indicated that perceived are more important than retinal image relations but that the latter may contribute to the illusory effect.

The Ponzo perspective illusion has often been considered to result from misapplication of three-dimensional spatial cues when a two-dimensional drawing or photograph is viewed (Fihlene, 1898; Gregory, 1963; Tausch, 1954; von Holst, 1957). These interpretations imply that an inappropriate cue to depth given by the converging lines to the figure is the principal determinant of the illusion. This view is supported by the results of a study by Leibowitz et al (1969), which demonstrated that the magnitude of the Ponzo illusion is sensitive to perceptual cues in addition to perspective and, in general, is enhanced by a context rich in depth cues. Alternative interpretations, generally physiological in nature, have been submitted to explain the illusory effect (Chiang, 1968; Ganz, 1966). These theories hypothesize that the spatial relations within the Ponzo figure, and consequently of the retinal image, are responsible for the illusion rather than misapplied depth cues. Fisher (1968a) has stated the problem between these opposing viewpoints succinctly: "Do the distance cues provided by such contours as the obliques of the Müller-Lyer illusion and Ponzo figures induce illusions or is the presence of the contours themselves responsible?" A third category of interpretations of the Ponzo illusion is based on the contrast of the distance separating the ends of the two parallel lines from the converging lines (Quina \& Pollack, 1971; Virsu, 1967). It is not clear, however, in either the depth cue or contrast theories whether the perceived or retinal relations between the components of the Ponzo figure give rise to the illusion. The present experiment addresses itself to this question by creating a viewing situation in which the converging lines of the Ponzo figure are perceptually disassociated from the two comparison lines by separation in depth. In this situation, stereopsis serves as the primary perceptual cue for separation of the components of the figure while maintaining essentially the same retinal image.

\section{SUBJECTS}

Twenty-four undergraduate volunteers, 10 female and 14 male, ages 18 to 24 , served as Ss. All exhibited $20 / 20$ far acuity with each eye and stereo acuity of at least $40 \mathrm{sec}$ of arc as measured by a Titmus professional vision tester.

\section{APPARATUS}

The stimulus consisted of a background of converging lines (see insert, Fig. 1) located $4.57 \mathrm{~m}$ from $\mathrm{S}$ and two sets of comparison and standard lines. One set was located directly on the background, and the other was mounted on a glass sheet located $33 \%$ nearer to $S$ than the background.

The background of 11 black lines, sheet, converged vertically to an apex $2.16 \mathrm{~m}$ from the floor and subtended $22.6 \mathrm{deg}$ of visual angle in height and $17.10 \mathrm{deg}$ of visual angle in width. The $.7 \mathrm{~cm}$ wide, mounted on a white cloth standard bar located directly on the background was below the apex of the converging lines. The standard lines subtended $6.36 \mathrm{deg}$ of visual angle. A series of 20 comparison lines ranging from 45.72 to $69.85 \mathrm{~cm}$ in length were individually presented parallel to and $107.95 \mathrm{~cm}$ below the standard. Each size increment of the comparison lines represented $2.5 \%$ of the standard length. The second set of standard and comparison lines, scaled to the same visual angle size and positioned in the same visual angle relation to the background as the first set, were mounted on a glass sheet, $.86 \mathrm{~m}$ high and $1.83 \mathrm{~m}$ wide, located $3.048 \mathrm{~m}$ from the $S$. Both displays were perpendicular to and centered on the line of sight of S's right eye. Luminance of the white background sheet was $4.47 \mathrm{fL}$ and that of the background, standard, and comparison lines was $.17 \mathrm{fL}$.

\section{PROCEDURE}

Each S, with his head held by a chinrest, viewed the Ponzo figure under the two display conditions, i.e., with the standard and comparison lines directly on the background (nonseparate condition) and with the standard and comparison lines on the glass sheet (separate condition). Each display condition was viewed both monocularly with the right eye and binocularly. Orders of presentations of display and viewing conditions were counterbalanced across Ss. The glass sheet was removed from S's field of view while viewing the display under the nonseparate conditions.

Within each condition, the comparison lines were presented in

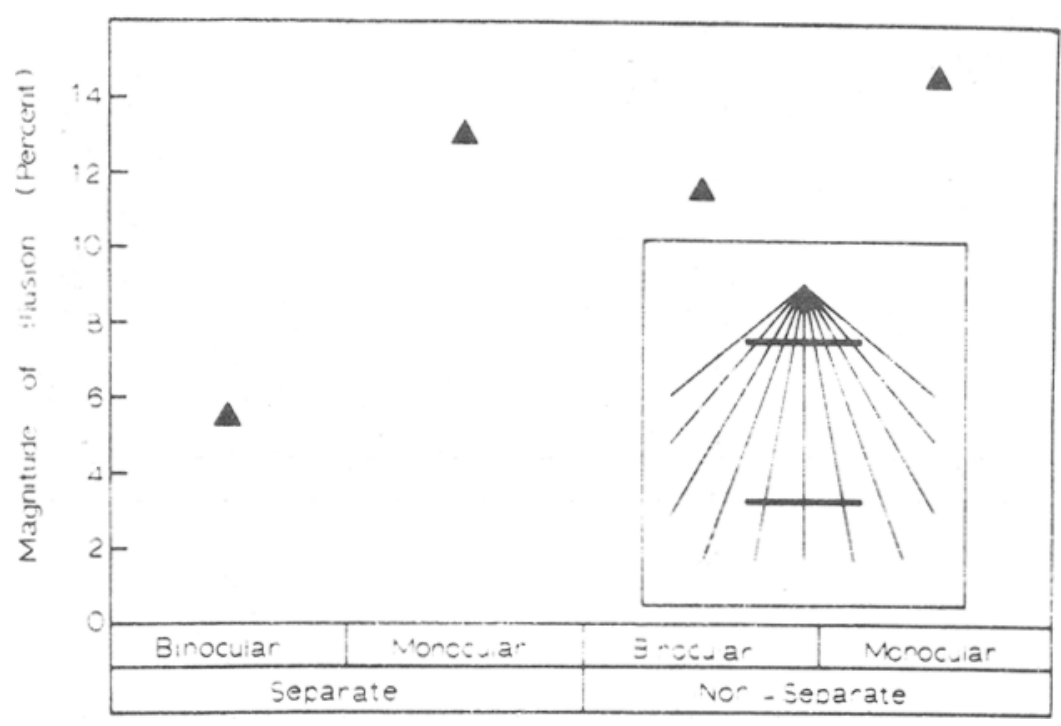

Fig. 1. Insert: the Ponzo perspective illusion. In this example, the two horizontal lines are of equal physical length. The data represent the magnitude of the Ponzo illusion for the various conditions of the experiment. 
random order, and $\mathbf{S}$ was asked to indicate whether the bottom line was physically longer or shorter than the top line. Judgments of equal were not allowed. The length of the comparison line subjectively equal to the standard was calculated as the midpoint between the two lengths where a clear transition in judgments occurred. If a clear transition was not apparent from S's responses, the comparison lines in the questionable range were shown again.

\section{RESULTS}

The mean data for the four observation conditions are plotted in Fig. 1 as percent illusion. A repeated-measures analysis of variance revealed significant differences for display condition $(F=19.1, \mathrm{df}=1,23$, $\mathrm{p}<.01$ ), viewing condition $(\mathrm{F}=59.8$, df $=1,23, \quad \mathrm{p}<.01)$, and their interaction $(F=13.7, \quad d f=1,23$, $\mathrm{p}<.01$ ). Duncan's modified (Bayesian) least-significant difference test indicated a significant difference $(\mathrm{p}<.05)$ between the binocular separate condition and all others. Also, the binocular nonseparate condition was significantly different $(p<.05)$ from the monocular nonseparate condition.

\section{DISCUSSION}

It is clear from the data that the binocular separate condition produced the least amount of illusion. This result could easily fit theories such as depth cue or contrast models which assume that the perceived relation between the comparison lines and the converging lines is an important determinant of the illusion.

The present results are of relevance in relation to Gogel's adjacency principle (1965), which states that cue effectiveness is inversely related to relative separation of the objects. This principle has been found to apply to depth as well as to lateral or directional separation (Gogel, 1972; Gogel \& Koslow, 1971; Gogel \& Mershon, 1969). Therefore, the effect of the converging lines of the Ponzo illusion upon the standard and comparison lines would be expected to decrease as these lines are displaced in depth from the perceived distance of the converging lines. It would be difficult to predict or explain this result by a theory which assumes the retinal image relations alone are the primary factors contributing to the illusion.

The difference between the binocular and monocular nonseparate conditions is also consistent with the depth cue interpretation. A depth interpretation would predict that in the monocular nonseparate condition, the line nearer the apex of converging lines would normally be perceived as more distant than the comparison, since with binocular viewing, stereopsis would tend to localize the two lines in the same plane and thereby reduce any perceived depth difference between them. A significant but small difference was found between these conditions which would tend to support the depth theories as opposed to the hypothesis that the presence of contours per se are a major contributing factor to the Ponzo illusion.

A possible objection may be raised that accommodation to the near lines would tend to obscure the influence of the background on the illusion. However, this does not seem to be a reasonable objection, since the accommodative distance between the comparison lines and the background is only .11 diopter. It has been shown (Westheimer, 1953) that the depth of focus or a range of clear vision is at least twice this amount for conditions which obtained in the present experiment. Secondly, if a difference in image quality for the two distances were responsible for the reduction of the illusion, a similar reduction in the monocular near condition would be expected. This clearly has not occurred.

It should be noted that while stereo separation greatly reduced the illusion, it was not completely nullified. The residual $5.6 \%$ illusion may reflect countervailing influences of other cues such as height in the visual field or may reflect the contribution of image contour interaction. While the above results are compatible with depth-cue and contrast theories as opposed to a strict retinal contour interaction hypothesis, they do not completely rule out the possibility of multiple contributing factors to the illusion. Some illusion is present in even very severe distortions of the Ponzo figure, where normal perspective cues are greatly reduced or absent (Fisher, $1968 \mathrm{~b})$. It is proposed that both retinal contours and perceived relations of the components of the Ponzo figure are contributing, in different ways, to the illusion.

\section{REFERENCES}

CHIANG, C. A new theory to explain geometrical illusions produced by crossing lines. Perception \& Psychophysics, 1968, 3, 174-176.

FILEHNE, W. Die geometrisch-optischen Täuschungen als Nachwirkungen der im korperlichen sehen erworbenen Erfahrung. Zeitschrift für Psychologie und Physiologie der Sinnesorgane, 1898. 17. 15-61.

FISHER, G. H. An experimental and theoretical appraisal of the inappropriate size-depth theories of illusions. British Journal of Psychology, 1968 a, 59, 373-383.

FISHER, G. H. An experimental comparison of rectilinear and curvilinear illusions. British Joumal of Psychology, 1968 b $59,23-28$.

GANZ, L. Mechanism of the figural aftereffects. Psychological Review, 1966, 73, $128-150$.

GOGEL, W. C. Size cues and the adjacency principle. Journal of Experimental Psychology, 1965, 70, 289-293.

GOGEL, W. C. Depth adjacency and cue effectiveness. Journal of Experimental Psychology, 1972, 92, 176-181.

GOGEL, W. C.. \& KOSLOW, M. The effect of perceived distance on induced movement. Perception \& Psychcphysics. $1971,10,142-146$

GOGEL, W. C., \& MERSHON, D. H. Depth adjacency in simultaneous contrast. Perception \& Psychophysics, 1969, 5, $13-17$.

GREGORY, R. L. Eye and brain. New York: McGraw-Hill, 1966.

L E I B OW I T Z, H .. BRISLIN, R., PERLMUTTER, L.. \& HENNESSY, R. Ponzo perspective illusion as a $m$ anifestitation of space perception. Science, $1969,166,1174-1176$.

QUINA, K., \& POLLACK, R. H. A parametric investigation of the Ponzo illusion under conditions of tachistoscopic exposure. Proceedings of the American Psychological Association, 1971,77-78 (Summary).

TAUSCH, R. Optische Tauschungen als artifizie 11 e Effekte der Gestaltungsprozesse von Grossen und Formenkonstanz in der natürlichen Raumwahrnehmung. Psychologische Forschung, 1954, 24, 299-348.

VIRSU, U. Contrast and confluxion as components in geometrical illusions. Quarterly Journal of Experimental Psychology, 1967, 19, 198-207.

von HOLST E Aktive Leistungen der menschlichen Geisichtswahrnehmung. Studium Generale, 1957, 10, 231-243.

WESTHEIMER. E. The effects of spectacle lenses and accommodation on the depth of focus of the eye. American Journal of Optometry, Monogr. 161, October 1953. 